\title{
Effect of Aluminum Concentration and Process Control Agents on synthesis of $\mathrm{Al}_{\mathrm{x}} \mathrm{CoCrFeMnNi}$ Alloys.
}

\author{
M.A. Ruiz-Esparza-Rodriguez ${ }^{1}$, C.G. Garay-Reyes ${ }^{1}$, I. Estrada-Guel ${ }^{1}$ and R. Martinez-Sanchez ${ }^{1}$. \\ 1. Centro de Investigación en Materiales Avanzados (CIMAV), Laboratorio Nacional de \\ Nanotecnología, Miguel de Cervantes 120, 31136 Chihuahua, Chih., México.
}

The structural study on high entropy alloys (HEA's) or multicomponent systems (MS) can be predicted by measuring the value of valence electron concentration (VEC), atomic radius difference $(\Delta \delta)$ and enthalpy of mixing $(\Delta \mathrm{H})$ [1]. However, the theoretical considerations are based on an ideal process free of variants in the system. The mechanical alloying (MA) process is a technique very used for synthetize HEA. The principal disadvantage of process is the contamination of the powders during milling, which depends of the material used in the container and milling balls, in addition to the process control agent (PCA) [2]. Thus, determining an appropriate PCA is important because allows achieve an optimal balance between the fracture and cold welding of particles during the milling process and controlled the oxidation of powders. The aim of this work is evaluate the effect of $\mathrm{Al}_{\mathrm{x}}(\mathrm{x}=0.5,1,1.5)$ addition, the crystal structure, and the oxidation of HEA using different PCAs during MA and compare the results with the theoretical calculations.

$\mathrm{Al}_{\mathrm{x}} \mathrm{CoCrFeMnNi}$ powders were processed by MA. Pure elements (each of them at least $99.9 \%$ purity) were used as the raw material. A high-energy mill Spex 8000 was used during MA process. The container is done by hardened steel to prevent external contamination with other elements out of the HEA designed. Ar atmosphere was used to avoid the presence of oxygen during the MA. Milling conditions were set to $10 \mathrm{~h}$ of milling time, powder mass $8.5 \mathrm{~g}$ and a ball-to-powder ratio of 5:1. In order to investigate the effects of PCA on the MA process, methanol, stearic acid and n-heptane were chosen as PCAs. The study of oxidation and structure of HEA were carried out by means of a thermogravimetric analyzer SDT Q 600 TA, elemental analyzer CHNS-O CE EA 1110, Panalytical $\mathrm{X}^{\prime}$ Pert PRO x-ray diffractometer and transmission electron microscope JEOL JEM 2200FS+CS.

Figure 1 shows the thermograms (TG) and oxygen quantification (OQ) present in the alloyed powders after the MA process. A decrease in the OQ with the use of stearic acid and n-heptane is observed. The OQ for methanol present higher values, so the thermogram indicates that there is no gain in weight because to previous surface oxidation in the HEA powders. It is concluded that the PCA influences in the OQ that can be generated in the HEA powders after the MA. Theoretically, the variation of aluminum in the alloy of high entropy modifies the VEC. However, it must be taken into account that only provides the ideal conditions. The results in figure 2 indicate a biphasic region $\mathrm{BCC}+\mathrm{FCC}$ in the case of the $\mathrm{Al}_{0.5} \mathrm{CoCrFeMnNi}$ and $\mathrm{AlCoCrFeMnNi}$ alloys while for the $\mathrm{Al}_{1.5} \mathrm{CoCrFeMnNi}$ alloy a single phase BCC is indicated. However, the experimental results concluded that the ideality of the theoretical calculations is lost through the MA process due to the variants that occur in the system. Figure 3 shows $\mathrm{X}$-ray diffraction patterns supported by electrons diffraction patterns taken on random particles, which indicate that the $\mathrm{Al}_{1.5} \mathrm{CoCrFeMnNi}$ alloy has biphasic structure $(\mathrm{BCC}+\mathrm{FCC})$ and not monophasic as it was indicated by the VEC.

References: 
[1] Sheng, Guo., Chun, Ng., Jian, Lu, \& C. T. Liu. Effect of valence electron concentration on stability of fcc or bcc phase in high entropy alloys, (2011). Journal Of Applied Physics, Volume 109.

[2] C. Suryanarayana, Mechanical alloying and milling, Prog. Mater. Sci. 46 (2001), p. 1-184.
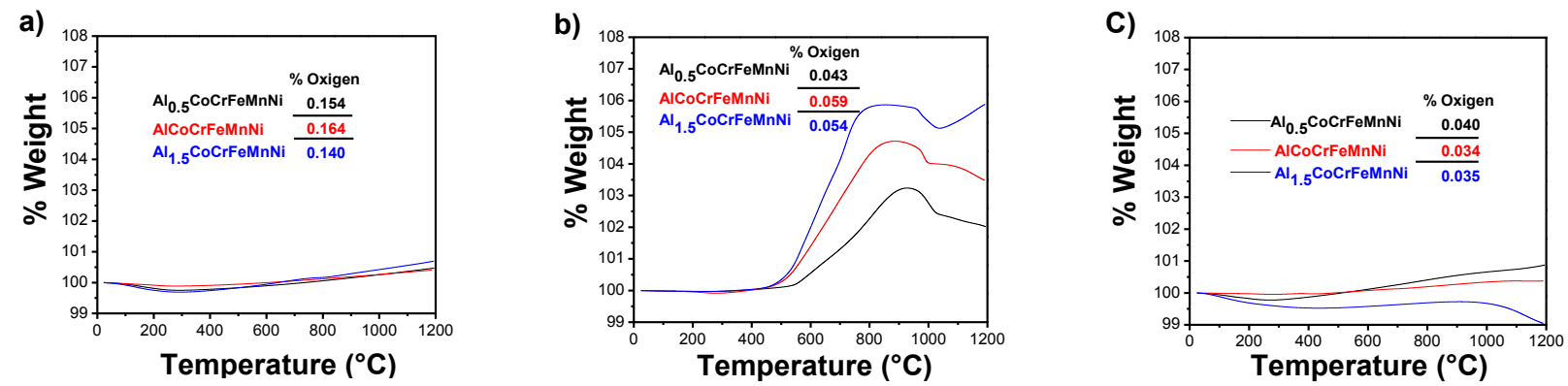

Figure 1. TGA graph/oxygen quantification in $\mathrm{Al}_{0.5} \mathrm{CoCrFeMnNi}, \mathrm{AlCoCrFeMnNi}, \mathrm{Al}_{1.5} \mathrm{CoCrFeMnNi}$ alloyed powder with different PCA, a) Methanol, b) Stearic Acid and c) N-heptane.

\begin{tabular}{cccc}
\hline & Alo.5CoCrFeMnNi & AlCoCrFeMnNi & Al1.5CoCrFeMnNi \\
\hline$\Delta \delta$ & 4.71 & 5.56 & 5.93 \\
$\Delta S$ & -13.87 & -14.13 & -14.77 \\
VEC & 7.58 & 7.16 & 6.75 \\
Structure & BCC+FCC & BCC+FCC & BCC \\
\hline
\end{tabular}

Figure 2. Theoretical calculation for $\mathrm{HEA}$ alloyed powder, $\mathrm{Al}_{0.5} \mathrm{CoCrFeMnNi}, \mathrm{AlCoCrFeMnNi}$ and $\mathrm{Al}_{1.5} \mathrm{CoCrFeMnNi}$.
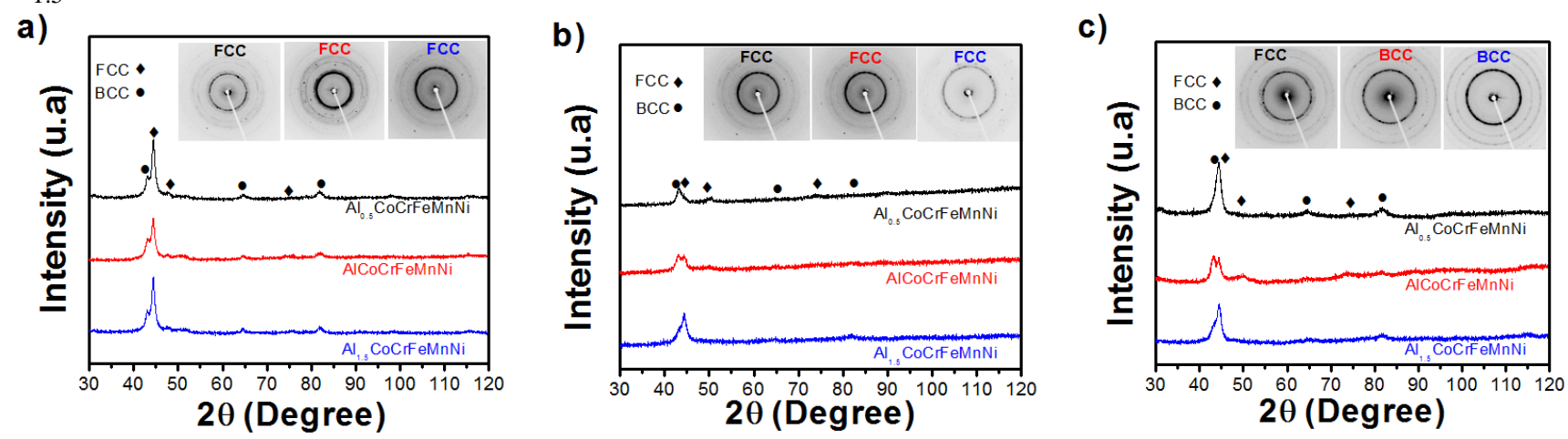

Figure 3. $\mathrm{X}$-ray diffraction patterns of the $\mathrm{Al}_{0.5} \mathrm{CoCrFeMnNi}, \mathrm{AlCoCrFeMnNi}$ and $\mathrm{Al}_{1.5} \mathrm{CoCrFeMnNi}$ alloyed powder with different PCA, a) Methanol, b) Stearic Acid and c) N-heptane. 